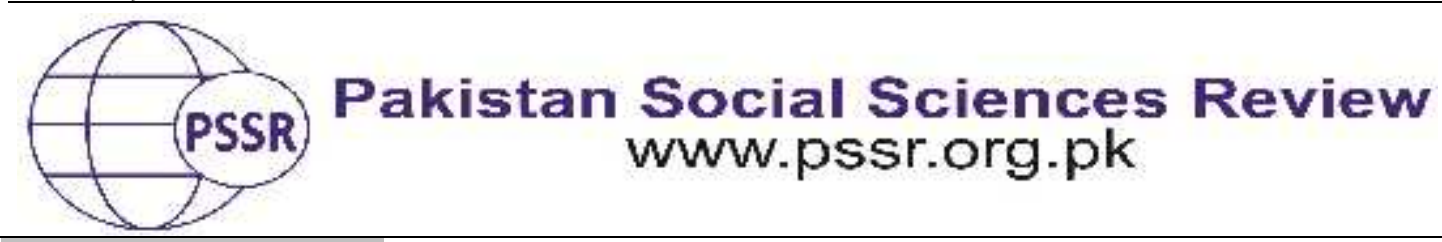

RESEARCH PAPER

\title{
Effectiveness of Local Government Systems, Pro-Poor Budgeting, and Policies for Marginalized Communities
}

Dr. Ghulam Mustafa1 Naseem Anthony ${ }^{2}$ Muhammad Arslan ${ }^{3}$

1. Assistant Professor, Department of Political Science \&International Relations, Government College University Faisalabad, Punjab, Pakistan

2. Research Assistant, HEC Thematic Project, Department of Political Science \& International Relations, Government College University Faisalabad, Punjab, Pakistan

3. Research Associate HEC Thematic Project, Department of Political Science \& International Relations, Government College University Faisalabad, Punjab, Pakistan

- This paper is the part of HEC Project Under Thematic Research Grant Programme 2017-18

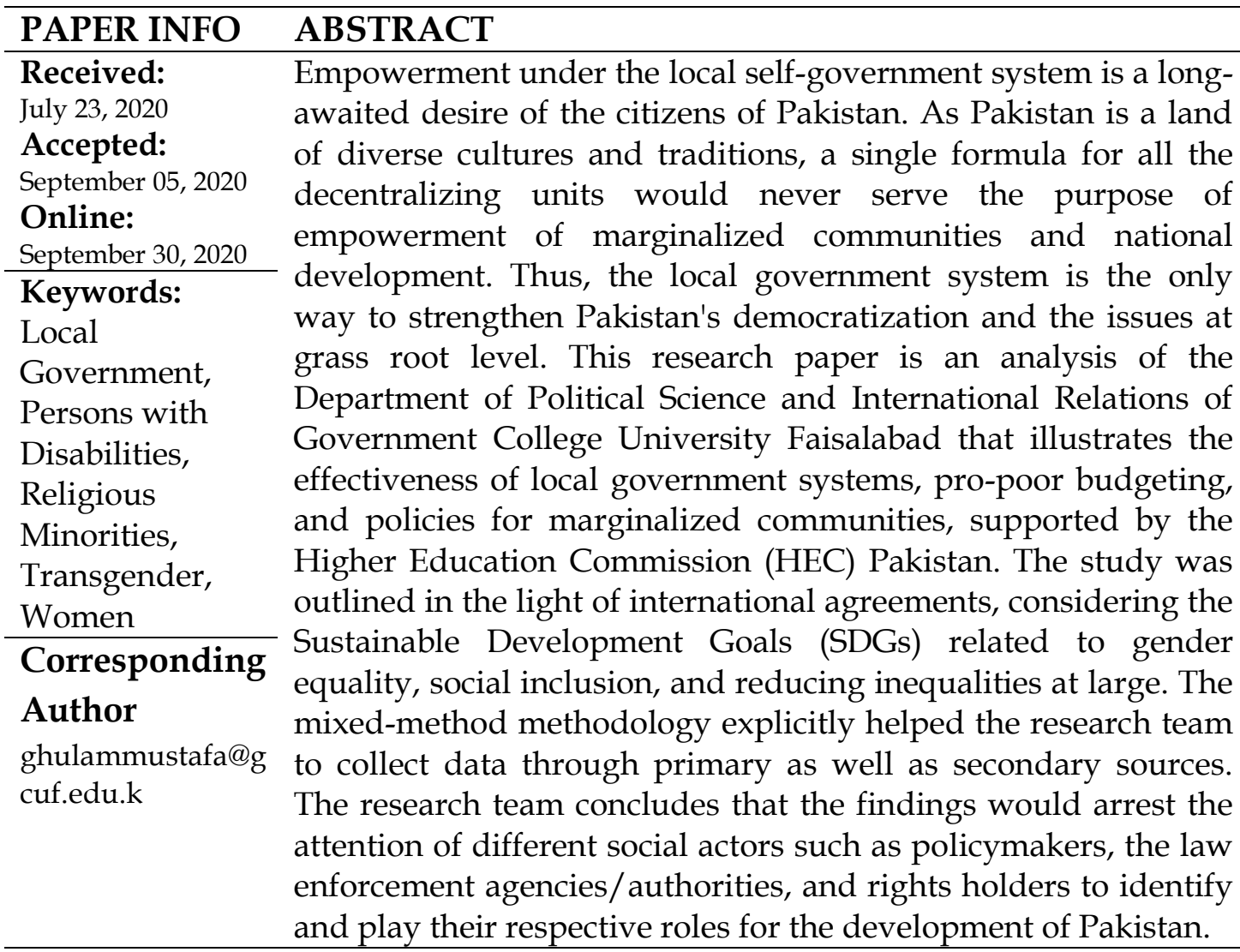

\section{Introduction}

Pakistan emerged as an independent state due to the political movement of the visible minority of Sub-Continent of India that converted the minority into a majority(Anthony, 2019). The sole purpose of the campaign was to have a piece of 
land where the people of faith can exercise their fundamental freedoms and liberties. The initial political leadership (then) focused on pro-poor policies, pro-poor budgeting, and adopting the principles of democracy. Conversely, the Quaid's untimely death created a vacuum filled by those who have not paid attention to public good yet grabbed the opportunity for their gains(Moskalenko, 2013). The Quaid's first speech to the first sovereign legislative body(President's Address, Honorable Quaid-i-Azam Mohammad Ali Jinnah to first sovereign legislative body August 11,1947) gave a clear message of equality of citizenship and opportunities. The Quaid further ensured that in terms of a nation, everyone is equal before the law and further guarantee the civil and political rights of the citizens of Pakistan. There is no doubt in the inordinate delay to draft a constitution, late transfer of the committed resources from India, and inclusion of feuds and non-democratic elements in the decision-making bodies amounted to the challenges for ensuring the Quaid's vision of equality of citizenship and opportunities(Rais, 2017). Later on, the interruption of the non-political actors in the political process further undermined the democratic institutions resultantly weaken the democratization in Pakistan. In the same context, the space for women and minorities in the political arena had squeezed (Ispahani, 2017).

The local self-government system is acknowledged as a basic unit of a democratic process. Therefore, it is the only method to ensure the engagement of all segments of society in the decision-making process(Saqib, 2008). In the case study of Pakistan, it is very astonishing, the democratic government never paid their heeds to the public's demand of the local government system, but the dictators always strengthened this component and tried their best to ensure the inclusion of all segments of the society. The provincial government system establishes a mechanism for the deprived or disempowered groups to communicate their concerns to the lawmakers and law enforcement agencies. By strengthening the local government system, it is straightforward to achieve the desired social development outcomes. Not-with-standing the constitutional provision, the political parties who claim themselves democratic one whenever assumes the mandate never intended to strengthen the local government system.

When it comes to women's participation in Pakistani politics, the national statutes and international agreements - particularly Sustainable Development Goals (SDGs) - are of great importance in discussing inclusion and reducing inequalities. Despite mushrooming legislation and allocating resources, the women remain marginalized sections of the society who are suffering discrimination, exploitation, and stereotypical attitudes of society. Though the constitution forbade the authorities for partial laws and policies, yet it has not defined any criteria or surveillance mechanism to ensure such an impartial arrangement. Similarly, the context further increases the marginalization of other groups, such as persons with disabilities, transgender people, and religious minorities.

Notwithstanding the constitution of Pakistan, 1973 provides grounds to take measures for the empowerment of deprived groups for neutralizing their 
marginalization (Mughal, 2011). However, the weak political will, along with unequal distribution and unrealistic allocation of resources, encouraged the marginalization of the vulnerable segments. The inconsistent political processes, partiality in decision-making, and diversion from real issues are other factors that affect the social fabric of Pakistan (Rais, 2017). Such context afforded a very conducive environment to those stakeholders who have a specific mindset and are not in favor of equality of citizenship to assume the powers and practicing their ideology overtly. Therefore, a visible gap divided the state and the general public; hence, the systemic discrimination encouraged the exclusion of minorities, persons with disabilities and transgender people.

Persons with Disabilities (PWDs), in the same context, are another marginalized section that was the focus of our research. As per the research team, disparities of rights in policies and laws can never ensure the equality of status and treatment. Such inequality, if it gets the legal cover, increases the marginalization of the weak segment of society and is gradually excluded from the mainstream. No doubt, the epoch of globalization of indifferences encouraged division within the community. Consequently, the weaker segments, including Persons with Disabilities (PWDs) forced to live on the margins of their life and their vulnerability is increased to receive discrimination and exploitation (Jacob, 2019).

Thus, the share and contribution of Persons with Disabilities (PWDs) in national development are counted insubstantial. In the context of Pakistan, PWDs are mostly unseen, unheard, and uncounted. In return, they face a multitude of social, economic, physical, and political barriers that are hampering their mainstream in different arenas in general and political spheres in specific. In addition to this, the stereotypes, primitive attitudes, and social stigma associated with disability have further provided available grounds for social exclusion (Anthony, Strengthen the Capacities of Persons with Disabilities to access Reserved Access Facilities, 2020).

Notwithstanding the complexity of the context, PWDs, and the organization of/for PWDs mobilized to challenge stereotypes that encourage the social exclusion of PWDs. It is self-evident, to find a break-through from societal dogma is a bit challenging task. It is pertinent to comprehend the gravity of the issue related to disability in a broader context before tackling it in a context. It's a complex and contested idea in most societies and requires dynamic and multidimensional strategies for approaching this issue.

Several focused group discussions were conducted to grasp the issue's gravity by engaging with the concerned groups. The research study adopted a conceptual framework that considers all the contextual factors, both individual and societal, that interplay with the disability and functionality of the PWDs.

International human rights framework particularly Convention on the Rights of Persons with Disabilities (CRPD) provided reasoning for focusing social inclusion 
and respect for diversity on facilitating PWDs instead of a limited and reductionist 'medical model' as the PWDs argued that it is the society that limits their role rather than their bodies. In the same manner, the Sustainable Development Goals (SDGs) 5, 10, and 11 are further afforded the grounds to discuss inclusion and reduce inequalities and empowerment.

In the same context, religious minorities have been engaged in this research study, and the research team conducted discussions and interviews with key leaders. Every individual possesses a multi-layered identity; concerning it, the identity related to language, culture, and religion is one of many. The inappropriate process of unifying the identities obscures several critical features of permanent and nonpermanent identities that affect the social fabric. One of the options is the institutionalization of minority representation incorporated in the international human rights framework or instruments. The mechanisms, devised for ensuring minority representation, should address the issue related to the representation of diversity within groups and that authorities should be aware of such diversity. Moreover, it requires seeking and considering the multi-dimensional approaches.

The debate around representation and participation in politics and public affairs of the diverse groups, including ethno-national, religious, and linguistic, is not new. Yet, the acknowledgment of minorities' rights to effective participation in public affairs and its codification in international human rights instruments (The General Assembly, 1981) was a novel to start with.

The researcher acknowledges the political participation of minorities as a key to full and effective enjoyment of rights by the minorities. In this regard, the quality of political representation is closely linked to the growth of political culture in general and overall democratic development. At the same time, the researcher believes that to reverse discrimination and underrepresentation, a robust legal framework, in the context of minority rights, is imperative for effective participation in all aspects of public affairs.

In the case study of Pakistan, it has been observed that the minorities in general and religious minorities particularly are being neglected and ignored by the policymakers. The general behavior of intolerance towards religious minorities further created such an environment that gradually excluded them. It has also been noted that laws and policies based on religious preference undermine the principle and objectives of equal citizenship. Thus, in light of international standards of human rights, national legislative frameworks must reflect international commitments' compliance.

Pakistan is a society of multiple identities and such an attribute making its institutional setup complex and complicated in terms of ensuring representation of diverse groups and addressing the issues of underrepresentation and discrimination. On the other hand, the various linguistic, ethnicity, culture, and religions present a social mosaic (Rais, 2017). 
The prime purpose of Pakistan's creation was to establish a society where people have liberty to celebrate their diversities. Conversely, the later practices distressed Pakistan's religious minorities as the commitments made by Muslim leaders at the sub-continent divisions were not translated into practice (Hussain, 2019). Thus, the struggle for preserving identity being as a minority group and participation in public affairs started with the invention of Pakistan.

As far as the representation and participation are concerned, the terms 'representation' and 'participation' are interlinked and are the essential ingredients for the inclusive model. To ensure representation and participation, though, can address the issues related to compliance in the light of international obligation. Yet, creating a feasible climate is a crucial one to ensure effective participation. The motives of these arrangements must aim at reversing the discrimination and addressing the underrepresentation.

In the same vein, the transgender people are another group that is facing the stereotypical and primitive attitudes of society(Arslan, Bhatti, \& GhulamMustafa, 2018). The society set up has squeezed the socio-economic as well as socio-political space. Therefore, this group is limited to adopting some specific professions, such as sex workers, pimps, beggars, and participating in celebrations as a dancer(Focused Group Interview, 2019). The transgender in Pakistan, like other weak segments, striving for the acceptance of their identity as equal citizens and struggling to break the cycle of marginalization by adopting another profession. The irony is that this group neither has the freedom to exercise their fundamental rights nor are accepted as complete human beings in the socio-religious context. In the recent past, the Supreme Court gave its verdict considering the issue of constitutional provisions of equality of citizenship and opportunities related to transgender people(Arslan, Bhatti, \& GhulamMustafa, 2018).

\section{Literature Review}

The political struggle of the pre-partition era, under the leadership of Quaidi-Azam, realized the inarticulate dream of Iqbal. We have not shaped the country as per the vision of the Quaid and Iqbal. The premature death of the Quaid and Liaqat Ali Khan's assassination further disturbed the state's fledgling democracy. The later practices also revealed that the political space had been dominated by such actors who solely focused on strengthening their positions rather than working on programs and policies. Resultantly, a culture of political intolerance is promoted that has hampered the non-traditional groups and newly emerging political groups for entering into mainstream politics. In consideration of such context, the issues related to women's participation, representation of religious minorities in legislative bodies, and inclusion of PWDs and transgender people in the political process are unattended and unaddressed.

Considering the research topic and its relevance to Pakistan's socio-political context, Shaista Suhrawardy Ikramullah has given strong reasoning to illustrate the 
elements that strengthened the political intolerance in Pakistan and increased the marginalization of the weak segment of the society particularly minority and women. According to her, the inordinate delay in approving the constitution, inadequate institutional setup, and recurring adjournment of the parliamentary sessions created a conducive environment for the non-democratic actors to hold powerhouses (Ikramullah, 2000). She further defines that delay to dispense the services to the citizens would mount frustration that would lead the country towards intolerance.

In the same manner, the issues related to de tug of war between executive and legislature around distribution of powers, and weak political institutionalization further corroborated by the Ian Talbot, renowned historian. He defines that the weakness of the political institutions, ignoring the factor of pluralism and conflicts at borders resulted strengthened the bureaucracy for controlling the reigns of the country as per their desire. He further argued that the first military coup culminated the democratic process in 1958(Talbot, 2015).

Similarly, the devolution of power plan (2000-2001) introduced by General Musharraf was appreciated by Muhammad Amjad Saqib. He opines that such a model of decentralization and inclusion of local leaders into politics is done the first time in the history of Pakistan. He further defined that the Musharraf's gestures to promulgate the devolution of power plan and to enhance the women's quota, the inclusion of minorities in the local body system was the part of the agreement between the World Bank and Government of Pakistan (Saqib, 2008). However, he further elaborated that, such an attempt was meant to bring the decision-making process closer to the community level by introducing changes in the institutional setup, improving the accountability mechanism and creating a space for the inclusion of women, laborers, and religious minorities.

In the same fashion, the matter of religious minorities and participation in politics was discussed by the Farahnaz Ispahani. As per her viewpoint, once the population of religious minorities was $23 \%$, it was now squeezed to 3\% (Ispahani, 2017). She held responsible for it the dismemberment of East Pakistan from the West Pakistan and inadequate legal frameworks, and discriminatory practices towards religious minorities. Her viewpoint - about the state of the religious intolerance and role of political actors - is an aide for understanding the trends and tendencies that gradually excluded the minorities from the decision-making processes at all levels.

In the context of religious minorities, Peter Jacob further provided grounds to examine the political participation of religious minorities in Pakistan. While giving his viewpoint about the plight of rights of minorities in Pakistan, he expressed that the quality of political representation is linked to political culture, which further depends on how the political culture developed (Jacob, 2017). Suppose the political culture gets nourished in democratic norms. In that case, the participation of minorities can be claimed as active participation in which the minority has the authority to influence the decision related to the day-to-day affairs of their social life 
(Jacob, 2017). Otherwise, it would be only limited for the sake of representation, not for actual participation.

Persons with Disabilities (PWDs) are a weak segment of the society that is compelled to live on the margins of their lives. Several stereotypes and myths are associated with them, such as disability is the punishment of God against the sins of parents. In this context, a thesis work of Nazia Sardar provided an understanding of incorporating the issues of political participation of PWDs in Pakistan. As per her views, persons with disabilities are the complete creation of God and possess the ability to participate in Pakistan's socio-economic development, but the societal setup and primitive attitudes do not allow them to utilize their strengths (Sardar, 2017).

Disparities and inequalities always create conflicts between the communities, with respect to it; Moonis Ahmar provided logical reason for assessing the trickledown effects of non-existence of local self-governments in Pakistan. He examined the Quaid vision and existing situation in Pakistan and opined that secular approach is the only tool that can reverse the discrimination and address the issues of underrepresentation of deprived sections of the society (Ahmar, 2014).

Likewise, Hamid Khan further provided the ground to assess the marginalization of weak segments of society in the context of the historical development of constitutions in Pakistan. According to him, Pakistan's painful history defines democratic and military rule experiences, and no outsider can feel the worse feelings of insiders who have suffered the taste of pseudo-democracy and quasi-dictatorship (Khan, 2017). He further exposed that the ruler who used Pakistan's land as a laboratory where the rulers are managing all kinds of constitutional experiments in different eras (Khan, 2017). His detailed study on political events in Pakistan shared the findings that helped us discussing the agenda of the empowerment of marginalized communities in the context of Pakistan's constitution.

\section{Material and Methods}

Since the research topic' effectiveness of local government systems, pro-poor budgeting, and policies for marginalized communities' is unique in its nature and a challenging task, as the marginalized sections' definition is not straightforward. Furthermore, the topic demanded to engage the different civil society organizations working on women's rights in general and civil and political rights in specific. Moreover, religious minorities, persons with disabilities, and transgender were also engaged in focused group discussions.

Furthermore, the mixed-method approach was adopted in which the primary and secondary data were gathered through different strategies and sources. Additionally, Key Informative Interviews were also conducted with various experts 
and veteran human rights defenders who are frequently raising the issue of empowerment of Pakistan's marginalized communities.

The research team, during the phase of literature review, along with other material, studies the document of Convention on the Elimination of All Forms of Discrimination against Women (CEDAW), Pakistan's Achievement regarding SDGs, Judgment of Justice Tassadaq Hussain Jailani 19 June 2014, Gender Parity Report 2017 and 18 of Punjab Commission on the Status of Women, Annual Reports of Human Rights Commission of Pakistan 2017-18 and 19, Report Election Commission on Gender Deficit in Voter Registration, Enabling the Empowerment of Women report of Association of Women for Awareness and Motivation, Legislative Watch of Aurat Foundation, and Human Rights Monitor of National Commission for Justice and Peace (NCJP). The mentioned material helped the research team to understand the issue in reality and set the criterion to finalize the stakeholders to be included in the research study. Such intervention also helped the team prepare two types of survey forms for the laypeople and representatives of the local government system and other experts.

The team has also conducted seminars in which the external expert was invited who presented their respective viewpoint in Pakistan's political culture and the political parties' role. From the government side, the Department of Human Rights and Minority Affairs Lahore, and the National Commission for Human Rights (NCHR) are worth mentioning. Ms. Corein Waheed (A Dutch National) participated in different sessions for presenting the acceptable practices of the Local Government System in the Netherlands. Simultaneously, Mr. Zahid Ul Islam compared Pakistan's political system that helped the research team identify the grey areas and factors that are barring the plan to proceed further. In the same pattern, Ch. Latif Nazar, Member Provincial Assembly of Punjab, former parliamentarians Dr. Najma Afzal and Mrs. Noor-un-Nissan Malik, representative of PCSW Ms. Shazia George, Mr. Peter Jacob, executive director CSJ-Lahore, Ms. Nazia Sardar executive Director AWAM, and Muhammad Noor-ul-Amin were engaged in different interventions during the research phase.

\section{Contextual Analysis}

Looking for the remedy to uniting a multi-ethnic society has been a primary focus of the politicians and civil society groups. However, the deep-rooted intolerance of ethnic groups towards other ethnicities would never achieve the desired goal of national unity and social cohesion. Similarly, the culture of political intolerance and practice to bar the traditional and new small political groups refrain from confronting the multi-facet challenges. Hence, the nation would lag-behind in the socio-economic development graph.

However, the role of a strategy a country devises aims at achieving the targets of national unity and socio-economic development worth-mentioning. In this perspective, some of the states are focusing on strengthening their systems adhered 
to democratic values to ensure the social inclusion of diverse groups in public affairs and guarantee the equality of citizenship irrespective of any discrimination. On the contrary, others would make false promises and try to hide the things under the carpet, and always turn their deaf ear towards the real issue.

Therefore, discussed in the latter, the issues concerned with the empowerment of marginalized sections of the society and pro-poor budgeting cannot be justifiable but keep the situation intact as the tall claims and unrealistic approaches can never serve the actual purpose.

In Pakistan, the issue related to democratic culture and strengthening of local government system has been emerging from time to time but unfortunately never is attended reasonably. The tug of war between political elites, weak democratization and poor political will to introduce pro-people laws and efficient implementation mechanism has multiplied the challenges.

The constitution of Pakistan 1973, through its articles 32 and 140-A, allowing the federating units of Pakistan to have their local self-governments as per their respective cultures, traditions, or demands of the people. Article 32 reads that the state shall encourage the provinces to establish their local governments (institutions). It further provides the grounds for the participation of peasants, workers, and women through special representation. Similarly, article 140-A in its section 2 also bound the provinces for establishing the local government systems, and the provinces are under obligation to devolve the political, administrative, and financial obligations to the elected public representatives(Pakistan, 1973).

In addition to it, Pakistan is the party to several treaties and agreements (United Nations Human Rights office of the High Commissioner, 2008), thus, responsible for such arrangements to ensure the inclusion of local communities into the political decision-making process. Most importantly, Sustainable Development Goals (SDGs), particularly SDG 5, 6, and 11, emphasize gender equality, social inclusion of marginalized sections, and reducing the inequalities. Pakistan's commitments to achieve the targets (short and long term) of SDGs cannot be achieved without establishing the local government institutions (Pakistan Institute for Parliamentary Services (PIPS), 2017).

During the literature review phase, and later in interviews, it was revealed that the definition of marginalized communities or sections of the society enshrined in the legislation related to the local government only defines the labor, women, and religious minorities. However, it does not discuss the political participation of persons with disabilities and transgender people (THE PUNJAB LOCAL GOVERNMENT, 2019).

To ensure participation, though, can address the issues related to compliance - in light of international commitments such as the UN Conventions and SDGs therefore, the state's obligation to create a feasible climate is crucial to ensure 
effective participation. In Pakistan's context, as the representation of religious minorities in the legislative body is concerned, neither the political parties nor the statutes have considered them in the political decision-making process. Though the state authorities have claimed that the minority representation exists in the committees and other legislative bodies, such a minority community model is only eyewash as they do not have control over the decision-making outcome. The research team has observed that existed mechanisms for ensuring minorities' presence in the decision-making process are not sufficient for implementing the right to the effective participation as accord to the constitution, specifically in the context of the chapter of Principles of Policy in the Constitution of Pakistan and as committed in the objective resolution.

In a democratic structure, the local government system is of prime importance that ensures grassroots communities' participation in political processes. In local self-government systems, an opportunity is created for electing the leaders of their own choice. The elected leaders are mandated to take necessary actions or measures for the welfare of the specific area's general public. The study about developed countries' political systems would reveal that developed countries have focused on strengthening the local self-government system and being afforded the mechanism for public participation in political decision-making processes. The local self-government creates a feasible environment for communities in the shape of small wards or councils for working together to promote peace, order, good governance, and poverty alleviation. This system provides an opportunity for people to decide about collections of their revenues and the proper utilization of their respective areas' development (United Nations, 2015)

Concerning it, the developed countries have invested their energies and resources to strengthen the local self-governments, which further resolve the community thresh-hold by adopting the welfare state concept. However, contrary to it, in Pakistan, the group's politics, rivalry, and enmity of political parties manipulated the system that eclipsed the system's effectiveness. Though the interim act of 1935 was adopted in Pakistan's inception phase, the vested interests of the elite powers interrupted the democratic process that weakens Pakistan's democratization. Such context gradually squeezed the political space for women, religious minorities, and other weak society segments (Khan, 2017). In the contemporary era, the persons with disabilities and transgender communities are the other visible groups that are raising their voice for their share in the political processes. In this regard, the research study focused the women, religious minorities, transgender people, and persons with disabilities for assessing the effectiveness of the local-self-governments in Pakistan and its trickle-down effects. 


\section{Political Participation of Religious Minorities}

There is a general agreement among the country's political actors and political forces about the need for comprehensive electoral reforms to strengthen democracy in the country. The religious minorities will also benefit from comprehensive electoral reforms, which will lead to empowering the political system and its stability by ensuring correct enrollment of the voters, polling of votes, transparent vote counting, and dependable results. It is quite obvious that the country faces huge challenges in the areas of the economy, the rule of law, peace and security, governance, and developing democratic institution, and that the country needs speedy and comprehensive structural, systemic and sect oral reforms to ensure the participation of religious minorities in the practical politics. Since the joint electorate restored in 2002 and a new reserve system based on proportional representation was introduced in good faith to incorporate minorities' voices in the elected bodies.

Yet, it did not lead to more outstanding quality among citizens and ending discrimination based on religion and belief in different life areas. It has been observed that there are laws and policies based on religious preference that undermine the principle and objectives of equal citizenship. These discriminations have to be eventually removed to bring the laws, policies, and practices to comply with international human rights standards. In such a context, the joint electorate system's fruits are still to be materialized, partly because the rationale and arrangement for the affirmative action is yet to be explained fully. Hence, there is a need for improving arrangements for minority representation in the country's economic, social, and political mainstream. The past experience shows that a genuine political representation remained elusive without parallel steps and arrangements for social justice through enhanced economic opportunities. Therefore, any method of political representation of minorities should lead to more affirmative action, such as reservations for admissions in universities and colleges, and effective and result based implementation of quota for jobs. Furthermore, the quality of political representation is closely linked to political culture's growth in general and overall democratic development in the country. The research study invited the decision makers' attention for a close examination of the existing system and efforts by the stakeholders to take the following concerns and issues into account in the electoral reforms.

The legislation for local government by the provinces reflects a lack of uniform understanding about mode of election for the reserved seats including for minorities. For instance, the Punjab Local Government Act 2013 leaves a room for manipulation of the reserved seats at the District Council and Urban Local Council (Metropolitan bodies).The Federal Ministry for Minorities Affairs was devolved to provinces under the $18^{\text {th }}$ Amendment in 2010 which deprived religious minorities of a voice at this important level of decision making. 


\section{Women's Participation in Practical Politics}

As far as the issue related to women's participation in politics is concerned, one can smoothly go through women's involvement in political affairs in the preparticipation era when the movement for a separate homeland was in full swing. Women were striving side by side to their males; conducted campaigns and visited door to door for mass mobilization to support the agenda of a separate homeland. Yet, given equality of participation in politics, the current context is not conducive to neutralizing a typical mindset that does not afford a visible space to women in powerhouses. Though a female served as the Prime Minister of Pakistan twice, the situation regarding women's visibility in political houses remains intact (Fleschenberg, 2009).

Conversely, since the inception of Pakistan (1947), as per case studies and reports by different institutions and organizations, the women made substantial inroads transforming themselves from invisible to visible and emerged as an organized and aware group determined to grab a space in political arenas. Yet, it is only limited to representation, and more energies and consisted of campaigns are needed to convert their image into participation. Moreover, when the women's space is analyzed by utilizing the indicator approach, it shows a little improvement; however, it cannot be claimed satisfactory. The unfavorable political culture in Pakistan failed to nurture the active participation of women in politics.

It revealed during the research study that

1. political leadership focused on male political leaders and not created a conducive political environment for nurturing the women's leadership, in the same context, the legal profession was another domain from where the women excluded,

2. The frequent attacks on democratic process weaken the democratization that undermined the democratic institutions as well as barred the non-traditional or other emerging social groups to find their space in political arenas,

3. Though the women succeeded in occupying space on the political landscape yet in unfavorable circumstances, they cannot acknowledge as an equal entity in strong patriarchy.

As far as the issue related to decision making of women at the household level is concerned, there is a perception that as members of a family, class, or profession, women's concerns and opinions are the same as of other members of that group and can be articulated equally well by male representatives. Such perception proved to be untrue. When choices have to be made within limited resources, women's concerns and priorities can differ from those of males. It is the difference that is ordinarily going on in the political arena where women have minimal representation and participation. 
In this context, inequity pervades all the political activity. In previous elections, there was a significant gender gap in voter registration observed. In the same context, the female voters' turnout was also not satisfactory (Rubab, Mustafa, \& Nawaz, 2020). Owing to this, the Election Commission of Pakistan (ECP) set a minimum ratio of women's votes in every constituency, and if any constituency failed to ensure female voters' turnout according to the specified ceiling, the result would be nullified. The discriminatory attitude towards women and considering them only for household chores are reasons for such less visibility in political activities.

Limitations in exercising the right to the franchise are a further barrier for women contributing to increasing women's invisibility in political activities. The ratio of obtaining National Identity Card (NIC), a mandatory and primary document to cast a vote, is also not satisfactory(Rubab, Mustafa, \& Nawaz, 2020), and the male members do not bother about it. Getting identity cards is generally not considered necessary for women and meets resistance from men. The process of getting an identity card also bears several bureaucratic hurdles owing to it; women and their relations bypass this process. Moreover, the mismatch of the names mentioned on the NICs of women and voters' lists usually barred the women for exercising their fundamental right who dare to come out from their houses. Therefore, most women hampered exercising their freedom of franchise, either because they do not have an identity card or for mismatch of their names.

\section{Analysis of Persons with Disabilities}

Elimination of disparity in legal rights is essential for building an inclusive society that guarantees equity and fundamental human rights for all the citizens. In the case of inconsideration, this can lead to the exploitation of society's marginalized segments, limiting their participation, representation, and acknowledgment. The epoch of globalization has imposed a superficial convergence to condense the diverse plural societies into indifferent dominant mainstream masses.

Consequently, the weak segments, i.e., Persons with Disabilities (PWDs), are forced to live on these societies' margins as they are more vulnerable to discrimination and exploitation. These ablest policies lead to the anti civilization of the PWDs and restrict the contribution of Persons with Disabilities (PWDs) in national development. Consequently, they face a multitude of social, economic, physical, and political barriers that are hampering their mainstreaming. The stereotypes, primitive attitudes, and social stigma associated with disability have further provided grounds for social exclusion and discrimination.

Despite the complexity of the context, PWDs and the organization of/for PWDs are mobilized to challenge stereotypes that encourage the social exclusion of PWDs and barring them from including into mainstream political practices. Finding a break-through from societal dogma is not a thoroughfare. It is pertinent to comprehend the gravity of the issue related to disability in a broader context before 
tackling it. This is a complex and contested idea in most societies and requires a dynamic and multidimensional strategy for approaching this issue.

The research team adopted a conceptual framework that considers all the contextual factors, both individual and societal, interplaying with the disability and functionality of the PWDs in our society. A psycho-social approach that focuses on making the PWDs as influential citizens in the cities.

International human rights framework, particularly the United Nations' Convention on the Rights of Persons with Disabilities (CRPD), provided reasoning for focusing social inclusion, political participation, reasonable accommodation, and respect for diversity to facilitate PWDs instead of a limited and reductionist 'medical model' as the PWDs argued that it is the society that limits their role rather than their bodies.

With the findings of numerous international, regional, and local researchers and organizations, now the research team has identified the role of social and physical barriers faced by the PWDs and various frameworks to evolve strategies. However, both the medical and social barriers are not mutually exclusive and demand a mixed-method approach that gives fair weightage to all the disability aspects.

We include people with impairments, activity limitations, or participatory restrictions in both the personal and societal lives of the peoples with disabilities under the broader category of the disability.

\section{Local Context}

The state recognized the PWDs in 1981 by launching the Disabled People (Employment and Rehabilitation) Ordinance that claimed to ensure the medical treatment, financial assistance, and employment opportunities and reserved a 1\% quota for the PWDs that was doubled in 1998(National Assembly of Pakistan, 2018)

In compliance with the Biwako Millennium Framework, a National Policy was developed in 2002, followed by a National Action Plan in 2006. A DirectorGeneral of Special Education and Social Welfare was assigned to implement the policy and legislation related to people with disabilities. A National Council for Rehabilitation of Disabled People (NCRDP), with its provincial chapters, was established to implement these policies and report the flaws. However, the provincial branches became autonomous after the 18th amendment in 2010(Ministry of Social Welfare and Special Education Islamabad, 2002).

On the other hand, the government issued a notification to the National Database Regulatory Authority (NADRA) to issue a National Identity Card with a disability logo for persons with disability and another notification for the disability 
concession cards in 2010. For accessing both mentioned above cards, the PWDs have to get a certificate from the District Social Welfare Department.

Despite this legal and institutional recognition of the PWDs, the community could not benefit from these facilities. These facilities are inaccessible for the PWDs because of the infrastructure, red-tapeism, and lack of awareness, segregated model, and government institutes' disinterest to deliver these services. In addition to this, their role in politics is only limited to cast their vote. Neither the political leaders nor their party manifestos considered the PWDs in the political activist category, thus only determining PWDs to play their marginal role.

In the absence of any rehabilitation plan of the government, the discriminatory practices against the PWDs have strengthened over the past few decades. The families and society rely on charity to serve the PWDs, which is a reductionist model. Local government system, though, focusing the empowerment of marginalized sections; however, the definition of marginalized sections is only limited to women and religious minorities. The policymakers have ignored persons with disabilities and the transgender community (Arslan, Bhatti, \& GhulamMustafa, 2018).

According to the analysis findings, NADRA issued 15,579 NICs with disability logo in Punjab in 2017 out of which 12,067 (77\%) were issued to men and only 3,512 (23\%) were issued to women. However, these numbers tell a lot about the provincial state of affairs, mainly male and female NIC holders. The research study has unfolded a new horizon of information for addressing social inclusion, focusing on political participation for the PWDs (The data is provided by an organization 'Association of Women for Awareness and Motivation' working for women, persons with disabilities and religious minorities).

\section{Language and the Community}

The language plays a pivotal role in the social inclusion for the PWDs. The research team use a standard term for the PWDs as it is used in the UN frameworks and also in the law so that people can understand it accordingly (AWAM). However, most of the terms are contested so we are going for the standard terms used in the law and the International Human Rights Institutes. During our interviews with the community, we found out that some community members do not like to be associated with the word 'disability'. In a rehabilitation institute, the children showed their displeasure on celebrating the disability day and made a point that this day should be dedicated to celebrating their abilities. They also argued that they already knew about their disabilities and there is no point in highlighting them in front of the people who cannot understand it. A Disability Rights Action Group (DRAG) member, Naad-e-Ali(A person with physically disability, music teacher and disability rights activist)shared his experience of meeting another wheelchair user who forbade Ali to call himself disabled that changed Ali's perspective on life and helped him resolve his identity crisis. 


\section{Conclusion}

The empowerment of marginalized communities and trickle-down effects of democracy is not possible without establishing local institutions. Good governance indeed allows the local people in local institutions to govern their systems by themselves. As society always consists of diverse groups and diversity can be seen in their socio-economic status and level of understanding towards different issues, however, in a democracy, such diversity never encourages the exclusion but the inclusion to strengthen the democracy through establishing local self-government for the self-governance system. Concerning it, Robert Dahl defined that the Local Self-Government system is the only system that ensures the Effective Participation of all adults and granting all adults to participate in the political process equally. Conversely, the practice of contemporary era, such type of democratic ideal has always been opposed by the plutocratic school of thought who believes that decision-making process is domain of the political elites and of those who are, as compared to the others, intellectually better. Therefore, such practices are more related to plutocracy rather than democracy. In Pakistan's case study, political history revealed that the local self-government system was not the primary objective of the democratic parties; contrary to it, the dictators always invested more energies and resources to strengthen the local institutions. Whatever their motives were behind such action, but it is an open fact. The democratic governments always focus on establishing a people-friendly environment for the partaking of the marginalized section of the society in the political process. Since Pakistan's constitution ensures the fundamental freedoms, including civil and political rights, however, notwithstanding such guarantees, denying the Local Self-Governments ipso facto is a denial of respecting and fulfilling civil and political rights. The exclusion of the marginalized section of society from the grassroots political processes such as persons with disabilities, religious minorities, transgender people, and women has muddled the true spirit of democracy and self-governed local governments. The research study revealed that the democratic forces have not allayed the concerns of the general masses regarding local self-governments and did not come up to the expectations of the general masses. The inordinate delay to announce local government elections and the inability to address the issues to the development of local communities has weakened the democratization in Pakistan.

\section{Recommendation}

To empower the grassroots communities in general, and marginalized sections of the society, including women, transgender people, persons with disabilities, and religious minorities in specific, it is imperative to establish local selfgovernments immediately.

The authorities must announce the quota for persons with disabilities and transgender people in local governments to establish arrangements for them to participate in the decision-making processes. 
Though there is a quota for women and religious minorities, they are not counted while making decisions; therefore, their representation must be converted into participation by suggesting and recommending improving the policy framework or other related procedures.

The authorities must invite suggestions and recommendations from the grassroots communities while finalizing the budget for ensuring the pro-poor budgeting. 


\section{References}

Ahmar, M. (2014). Conflict Management E Vison for a Secular Pakistan: A Comparative Stud. Karachi: Oxford University Press Karachi.

Anthony, N. (2019). Effective Political Participation of Religious Minorities in Pakistan: Joint Electorate and its Impacts on Society (M.Phil.Thesis). Political Science and International Relation Department G.C University Faisalabad.

Anthony, N. (2020). Strengthen the Capacities of Persons with Disabilities to access Reserved Access Facilities. Strengthen the Capacities of Persons with Disabilities to access Reserved Access Facilities. Faisalabad: Association of Women for Awareness and Motivation (AWAM) Faisalabad.

Arslan, M., Bhatti, D. M., \& GhulamMustafa, D. (2018). Legal Rights of Transgenders in Pakistan: Theory and Practice (Case Study of Faisalabad Division). Pakistan Social Sciences Review, 2(2), 106-116.

AWAM. (n.d.). Strengthen the Capacities of Persons with Disabilities for Accessing Reserved Quota. Faisalabad: Association of Women for Awareness and Motivation.

Fleschenberg, A. A. (2009). The Gender Faces of Asian Politics. Karachi: Oxford University Press Karachi.

Ikramullah, S. S. (2000). From Purdah to Parliament. Karachi: Oxford University Press Karachi.

Ispahani, F. (2017). Purifying the land of the Pure. New York: Oxford University Press New York.

Jacob, P. (2017). Electoral Reform and Political Representation of Religious Minorities: Working Paper. Faisalabad: Association of Women for Awareness and Motivation (AWAM).

Jacob, P. (2019). Social Justice. (P. Jacob, Performer) Department of Political Science and International Relations, GC University Faisalabad., Faisalabad, Punjab, Faisalabad, Pakistan.

Jamil, M. H. (n.d.). An Introduction to Political Science, by M. Hameed Ullah Jamil, published by:. Lahore: Khalid Waheed Malik, Lahore.

Khalid, M. T. (n.d.). Data Book on Sustainable Development Goals: Pakistan's Challenges and Opportunities. Islamabad: Pakistan Institute for Parliamentary Services Islamabad. 
Khan, H. (2017). Constitutional and Political History of Pakistan. Karachi: Oxford University Press Karachi.

Ministry of Social Welfare and Special Education Islamabad. (2002). National Policy for Disabled People 2002.

Moskalenko, V. Y. (2013). A Political History of Pakistan 1947 - 2007. Karachi: Oxford University Press Karachi.

Mughal, J. (. (2011). Principles of Policy, Constitution of Pakistan 1973. SSRN, 1-60.

National Assembly of Pakistan. (2018). Rights of Persons with Disabilities act 2018. Retrieved from http://www.na.gov.pk/uploads/documents/1545385013_141.pdf

Pakistan Institute for Parliamentary Services (PIPS). (2017). SDGs: Challenges and Opportunities. RESEARCH DIGEST JANUARY 2017.

Pakistan, C. o. (1973). Constitution of Islamic Republic of Pakistan Retrieved 09 10, 2020, fromhttp://www.na.gov.pk/uploads/documents/1333523681_951.pdf

Peden, J. B. (1929). Report of the Royal Commission on the Constitution. Canberra: Government Printer.

President's Address, Honorable Quaid-i-Azam Mohammad Ali Jinnah to first sovereign legislative body August 11, 1947, retrieved from Selected Speeches of Members of the Constituent. (1947). In National Assembly Vol. 1. Pakistan Institute for Parliamentary Services (PIPS).

Rais, R. B. (2017). Islam, Ethnicity, and Power Politics: Constructing Pakistan's National Identity. Karachi: Oxford University Press Karachi.

Rubab, M., Mustafa, D. G., \& Nawaz, A. (2020). Conundrum of Women Political Participation in Pakistan: Impediments and Opportunities. Pakistan Social Sciences Review, 4(2), 135-149.

Saqib, S. M. (2008). Devolution and Governance: Reforms in Pakistan . Karachi: Oxford University Press Karachi.

Sardar, N. (2017). An Analysis of Political Rights of PWDs in Pakistan, (2017) by Nazia Sardar, thesis work, Political Science and International Relations Department in GC University Faisalabad. Political Science and International Relations Department in GC University Faisalabad.

Talbot, I. (2015). A History of Modern South Asia: Politics, State, Diaspora . Karachi: Oxford University Press Karachi. 
The General Assembly. (1981, November). United Nations Human Rights office of the High Commissioner. Retrieved from Declaration on the Elimination of All Forms of Intolerance and of Discrimination Based on Religion or Belief: https://www.ohchr.org/EN/ProfessionalInterest/Pages/ReligionOrBelief.aspx

The Punjab Local Government. (2019). The Punjab Local Government Act 2019. Retrieved from http://punjablaws.gov.pk/laws/2735.html: http:// punjablaws.gov.pk/laws/2735.html

United Nations Human Rights office of the High Commissioner. (2008, April 17). UN Treaty Body Database. Retrieved from https://tbinternet.ohchr.org/_layouts/15/TreatyBodyExternal/Treaty.aspx?Co untryID $=131 \&$ Lang $=\mathrm{EN}$

United Nations. (2015). Sustainable Development Goals Knowledge Platform. Retrieved from Transforming our world: the 2030 Agenda for Sustainable Development: https:/ / sustainabledevelopment.un.org/post2015/transformingourworld

Watts, R. (1966). New Federations: Experiments In The Common Wealth. Oxford: Clarendon Press.

Wheare. (1947). Federal Government. New York, London: Oxford University Press. 